\title{
Una epistemología dialéctica para el análisis de la ciencia
}

\author{
A dialectical epistemology for the analysis of science \\ Miguel Angel Rendón Rojas \\ Universidad Nacional Autónoma de México. Instituto de \\ Investigaciones Bibliotecológicas y de la Información, México \\ marr@unam.mx \\ (iD https://orcid.org/0000-0002-9206-6511
}

\begin{abstract}
RESUMEN:
El objetivo de este artículo es encontrar una epistemología que permita fundamentar el conocimiento científico, responder las interrogantes que aparecen en su construcción y permita su ulterior desarrollo. Como metodología se utilizan métodos propios de la filosofía: la hermenéutica para la interpretación de textos, el análisis y síntesis para descomponer las ideas de los textos leídos y recomponerlos en una nueva visión dentro de la problemática analizada; y la deducción para obtener inferencias válidas a partir de esas ideas obtenidas. Se concibe a la epistemología no como una disciplina científica particular ni como una disciplina prescriptiva, sino como una rama de la filosofía que estudia la ciencia. Se propone el realismo dialéctico hermenéutico como marco filosófico que soporta y orienta esa epistemología buscada, por lo que se analizan el realismo, la dialéctica y la hermenéutica. Resultados: se justifican tanto un realismo alejado del dogmatismo estático que requiere un sujeto cognoscente pasivo, como un constructivismo apartado de subjetivismos y relativismos. Conclusiones: una epistemología realista dialéctica hermenéutica resulta útil para el análisis de la ciencia en general y de la ciencia de la información en particular ya que permite explicar el devenir de ambas y el problema de la relación entre teorías nuevas y antiguas; la inter y transdisciplina; así como el papel del sujeto y la sociedad en la construcción de la ciencia sin negar la objetividad.
\end{abstract}

Palabras clave: Epistemología, Realismo dialéctico hermenéutico, Ciencia de la información, Dialéctica.

\section{Abstract:}

The objective of this article is to find an epistemology that allows the foundation of scientific knowledge, to answer the questions that appear in its construction and to allow its further development. As a methodology, the following methods of philosophy are used: hermeneutics for the interpretation of texts, analysis and synthesis to decompose the ideas of the texts read and recompose them in a new vision within the analyzed problematic; and deduction to obtain valid inferences from those obtained ideas. Epistemology is conceived neither as a particular scientific discipline nor as a prescriptive discipline, but as a branch of philosophy that studies science. Dialectical-hermeneutic realism is proposed as the philosophical framework that supports and orients the sought epistemology, so realism, dialectics and hermeneutics are analyzed. Results: both a realism far from the static dogmatism that requires a passive knowing subject, and a constructivism away from subjectivism and relativism are justified. Conclusions: a dialectical-hermeneutic realist epistemology is useful for the analysis of science in general and information science in particular, since it allows to explain the evolution of both and the problem of the relationship between new and old theories; the inter and transdiscipline; as well as the role of the subject and society in the construction of science without denying objectivity.

KEYWORDS: Epistemology, Hermeneutical dialectical realism, Information science, Dialectic.

\section{INTRODUCCIÓN}

Una de las formas con ayuda de las cuales el ser humano asimila la realidad y al mismo tiempo se relaciona con ella es la ciencia. Ésta tiene además un status más reconocido que otras formas que cumplen la misma función de relacionarse con la realidad como son el conocimiento cotidiano, las tradiciones, el arte, la religión o la filosofía. Cuando se dice que la ciencia ha emitido un veredicto, eso significa que es verdadero, cierto (indudable), comprobado y necesario. Por lo anterior, resulta de vital interés poder identificar lo que 
es ciencia y distinguirla de lo que no lo es; además de que para un cuerpo de conocimientos también resulta importante que se le otorgue el calificativo de científico, porque eso eleva su reconocimiento y valor social.

La epistemología es la encargada de analizar los conocimientos científicos y determinar sus características, condiciones, límites y fuentes. Sin embargo, en el proceso de ese análisis se presentan problemas difíciles de responder y provocan discusiones en los que no se encuentran consensos, como por ejemplo la existencia o no de fundamentos de la ciencia; la necesidad de un universalismo del conocimiento científico o el surgimiento de ciencias localistas geográfica y culturalmente que se enfrentan al deseo de la universalidad visto como un eurocentrismo colonizador disfrazado y ellas mismas se proclaman conocimientos anticolonialistas emancipadoras; la relación entre teoría y observación, la razón y la empiria; la tensión de un racionalismo puro frente a la sociología del conocimiento, el giro lingüístico y el convencionalismo; el monismo o pluralismo metodológico, la necesidad de la matematización del conocimiento o la permisibilidad de metodologías cualitativas; la evolución acumulativa de la ciencia contra los cambios bruscos y totales de revoluciones científicas; la relación entre teorías que pueden ser vistas como incompatibles, contradictorias, subordinadas, o un caso extremo de una de ellas; la autonomía disciplinar o la transdisciplina, pasando por la multi e interdisciplina; entre otras cuestiones.

Así pues, se presenta a la epistemología una tarea no sencilla y consideramos que los problemas enumerados y otros que puedan presentarse no pueden resolverse desde una posición absolutista y dogmática, sino que sólo desde una posición que denominamos dialéctica se pueden encontrar soluciones que permitan comprender lo que es la ciencia y se encuentre acorde con la actividad de las personas que con sus investigaciones y descubrimientos la desarrollan.

\section{Metodología}

Para nuestro estudio hemos utilizado métodos propios de la filosofía como la hermenéutica cuya finalidad es llegar a la comprensión a través de la interpretación de textos. Asimismo, se utilizó el método del análisis y síntesis para descomponer las ideas de los textos leídos, llegar a sus elementos mínimos y presupuestos de los que parten, para después recomponerlos en una nueva visión dentro de la problemática analizada. Del mismo modo, se empleó la deducción, que consiste en obtener conclusiones a partir de consecuencias lógicas, esto es, a partir de enunciados verdaderos (premisas) se siguen otros enunciados (conclusiones) que necesariamente son verdaderos. De igual forma, se recurrió a la dialéctica como método de pensamiento que reconoce la tensión constante entre contrarios sin privilegiar uno de ellos ni trata de encontrar una síntesis que supere esa contradicción.

\section{RESUltados Y DisCUSIÓN}

\subsection{Epistemología o filosofía de la ciencia}

La epistemología la concebimos como filosofía de la ciencia, entendiendo por filosofía la disciplina que interroga la realidad buscando su sentido, su ser e identidad, las causas de su origen, fin y finalidad. Por consiguiente, la epistemología busca el sentido, ser e identidad de la ciencia y se pregunta por su origen y finalidad. De esta manera, la forma en que la epistemología encare esas preguntas y las respuestas que ofrezca dependerá del tipo de filosofía que se adopte y del que se parta. Por ejemplo, a partir del positivismo lógico se ve a la epistemología como una disciplina científica particular, armada con las herramientas que ofrece la lógica contemporánea, con ayuda de las cuales se analizan las teorías científicas y el ideal al que se aspira es que a semejanza de la lógica y las matemáticas, se formalicen dichas teorías, es decir, se simbolicen sus enunciados y componentes, los cuales necesariamente deben poseer un contenido empírico; al mismo tiempo, se eligen 
un conjunto de enunciados primitivos que se toman como axiomas (principios, postulados) y finalmente, a partir de éstos, aplicando reglas deductivas, se obtiene todo el contenido teórico de la ciencia en cuestión. Otra tarea encomendada a este tipo de epistemología es realizar un análisis lingüístico de las teorías con el objetivo no tanto de resolver problemas de la ciencia, sino disolverlos y desecharlos, al aclarar malentendidos o identificar pseudo problemas originados por el mal uso del lenguaje, porque

el objeto de la filosofía es la aclaración lógica del pensamiento [...] Una obra filosófica consiste esencialmente en elucidaciones. El resultado de la filosofía no son «proposiciones filosóficas», sino el esclarecerse de las proposiciones. La filosofía debe esclarecer y delimitar con precisión los pensamientos que de otro modo serían, por así decirlo, opacos y confusos (Wittgenstein, 2002, Proposición 4.112).

$\mathrm{Al}$ mismo tiempo, lo anterior significa que " $\mathrm{Si}$ se puede plantear una cuestión, también se puede responder" (Wittgenstein, 2002, Proposición 6.5), por lo tanto, únicamente es posible formular las preguntas que se pueden responder; si no tienen una respuesta, entonces ni siquiera pueden plantearse: "Para una respuesta que no se puede expresar, la pregunta tampoco puede expresarse" (Wittgenstein, 2002, proposición 6.5). Pero si pese a todo se insiste en plantearlas, lo que se obtiene son preguntas ilegítimas o pseudoproblemas.

Sin embargo, ese programa epistemológico no pudo realizarse porque la historia de la ciencia, en particular de las matemáticas y de la lógica, mostró la limitación del poderoso (pero no Todopoderoso) aparato de la lógica matemática. Una de esas limitaciones es el llamado teorema de Gödel de incompletud de la lógica de predicados, el cual consiste en la demostración de que siempre existirá un enunciado que es verdadero pero que es indemostrable dentro de ese sistema. Asimismo, se descubrieron algunas paradojas lógicas o semánticas en los fundamentos de la lógica. ${ }^{1}$

Otra visión de la epistemología es la aseveración que la ciencia "requiere de algo que la vigile, que la controle y garantice de esta manera que se acerca a la realidad. Es con este fin y en un proceso de vigilancia en el que surge la epistemología”. (Romero, 1981, p. 1). Es decir, existen unos principios que soportan el resto de los conocimientos. La tarea del epistemólogo es, primero descubrir tales fundamentos, y después, velar por que los científicos no se alejen de ellos. De esta manera, la epistemología se convierte en guía que conduce al conocimiento científico, el cual es por definición verdadero, necesario, universal, comprobado, modelo de todo conocimiento y por consecuencia produce certeza, absoluto consenso porque es "una locura" ir contra de él.

Esa creencia en unos fundamentos últimos la podemos rastrear a lo largo de toda la filosofía occidental, desde los presocráticos con los eleatas -Jenófanes, Parménides, Zenón, Meliso- (siglo VI-V A.C.), quienes concebían el ser como inmutable y eterno: "[...] las únicas vías de investigación que son pensables: Una, que es y que no es posible que no sea. [...] La otra, que no es y que es necesario que no sea” (Parménides, 1985, B2, 2-5). Posteriormente, apareció en las ideas de Platón y las propuestas metafísicas que consideran como realidades las esencias, substancias, o conferían el fundamento último a Dios. En la época moderna, los fundamentos se trasladan a las ideas claras y distintas, las verdades de razón, la idea absoluta, la correspondencia completa del mundo lógico con el mundo ontológico. Pensadores como Platón, Aristóteles, Descartes, Bacon, Locke, Hegel, Wittgenstein (del Tractatus), Husserl, entre otros, se incluyen dentro de esa tendencia.

Simultáneamente, se tiene fe en la razón para alcanzar esos fundamentos últimos, con ayuda de la experiencia, las matemáticas, y la lógica, lo que resulta en una visión optimista de alcanzar un conocimiento realmente verdadero e inamovible: el conocimiento científico.

Tampoco compartimos esa concepción de la epistemología. Desde nuestro punto de vista, la epistemología no es una disciplina prescriptiva que fiscaliza a las demás disciplinas y les indica normas, requisitos, condiciones que deben cumplir para que verdaderamente se hagan merecedoras del calificativo de científicas. La misma denominación "epistemología científica" no se justifica. Puede ser que la epistemología indique y decida cuál disciplina adquiere el rango de ciencia, pero no queda claro cómo y por qué ella misma es 
declarada científica. No existe una meta-epistemología que la analice y le reconozca su calidad de científica, y aunque la hubiera, entonces se necesitaría una meta-meta-epistemología que analizara a la anterior y así de manera sucesiva indefinidamente. Lo que encontramos en realidad es que esa primera epistemología toma sus principios de una filosofía, de ahí que esté ligada a un pensador o a una corriente filosófica.

En este momento podemos descubrir una contradicción en cuanto, como lo expresamos en un inicio, la ciencia como forma de asimilación de la realidad pretende ocupar un sitio privilegiado en comparación con otras formas semejantes, entre ellas la filosofía, porque aparentemente proporciona conocimientos verdaderos inequívocamente; pero, al mismo tiempo, su justificación se encuentra en la filosofía que está lejos de esa univocidad cognitiva.

Así pues, si la epistemología se desprende de una corriente filosófica, y es sabido que no existe un consenso entre las diferentes propuestas filosóficas, entonces tampoco existe un acuerdo sobre cuáles son esos fundamentos y cómo se llega a ellos. Las discusiones filosóficas continúan y continuarán sin llegar a una conclusión.

Al unísono, la realidad misma es compleja, multifacética, cambiante e infinita, puede aparecer con diferentes manifestaciones, por lo que descubrir unos fundamentos últimos e inamovibles aparece como una tarea imposible a menos que se hagan concesiones al dogma, a la autoridad, a una realidad metafísica. La situación se complica en el caso de las ciencias humanas y sociales porque el campo de estudio surge junto al sujeto y la objetividad parece diluirse. De esta manera, se presentan tres opciones: a) refugiarse en un reino metafísico de estilo platónico donde existen de cierta manera, aunque no se sabe muy bien cómo, entelequias que existen en sí de manera completa y autónoma, como pueden ser los eidos, realidades ideales, lo objetivo noreal (Frege, 1984, pp. 69-70), el tercer mundo (Popper, 1980), el sujeto trascendental; b) declarar la primacía de lo material como fundamento y reconocer la mente como un espejo en el que se refleja esa realidad; c) cansados de tantas discusiones filosóficas en los que no se llega a ninguna conclusión o por lo menos a un acuerdo mínimo, declarar que no existen tales fundamentos y por consecuencia dejar de buscarlos, por lo que se renuncia al llamado fundacionismo y se busca refugio en su opuesto, el anti-fundacionismo.

La segunda opción tampoco parece la más acertada porque la multiplicidad de interpretaciones de la realidad contradice la propuesta del conocimiento como reflejo. Por lo que queda la tercera posibilidad: el anti-fundacionismo.

\subsection{Anti-fundacionismo o fundacionismo inmanente}

Uno de los argumentos que se propone para adherirse al anti-fundacionismo consiste en que "no es posible determinar los fundamentos del conocimiento, ya que no existe algo así como los fundamentos." (Saraiva, 2020, p. 48) y más adelante "aclara" que "las pretensiones de cientificidad de la ciencia de la información no se resolverán mediante la búsqueda de una base filosófica, ya que esto es imposible puesto que no existe tal fundamento. (Saraiva, 2020, p. 49) [resaltado nuestro]. Pero por qué y cómo se llegó a esa conclusión no queda del todo claro. Cuando se critica el fundacionismo se concibe a éste como una propuesta epistemológica que responde a una visión del mundo donde existen unos fundamentos estáticos e inmutables: Los argumentos vertidos por el fundacionismo, en gran medida, presuponen la búsqueda de alguna estructura inmutable en el mundo, la existencia de elementos estáticos con la capacidad de fundamentar el conocimiento (Saraiva, 2020, p. 36) [resaltado nuestro].

Sin embargo, no se indica nada en contra de un fundacionismo débil o dialéctico, como veremos más adelante, donde el fundamento no es totalmente absoluto y estático, sino reconoce la simultaneidad de lo objetivo y subjetivo, lo absoluto y relativo, lo estático y dinámico; ni tampoco contra otras fundamentaciones (teórica, lógica, metodológica, extrateórica) que son internas a la disciplina y no buscan fundamentos externos (Rendón Rojas, 2005, pp. 45-48). Simplemente sólo se asevera de manera categórica su imposibilidad. 
Tal manera de argumentar nos recuerda el "profundo" razonamiento del personaje del cuento de Chéjov, Carta a un vecino erudito, donde Vasili Semi-Bulátov, Suboficial de los Cosacos del Don y Decano de la Nobleza, con absoluta certeza afirmaba: "eso no puede ser, porque no puede ser nunca" (Chéjov, 2013).

Sin embargo, podemos descubrir un equívoco en la declaración de que no hay que buscar fundamentos en el conocimiento científico. Al mismo tiempo que se niega la existencia de unos fundamentos, se proporcionan otros. Lo que en realidad se niega son unos fundamentos externos, por consecuencia objetivos, así como inalterables y completos; y en su lugar se ofrecen como justificación de la actividad científica otros que resultan ser internos, por tanto, subjetivos, y relativos (consensos, utilidad, poder, intereses, ideologías, modas intelectuales, imaginación, de naturaleza lingüística, etc.). Es decir, si bien ya no se buscan fundamentos trascendentes respecto a la ciencia, se señalan otros que son inmanentes a la actividad y sujetos que la construyen.

Lo anterior debido a que no se puede evadir el principio de Razón Suficiente, el cual, al igual que el principio de No Contradicción y de Identidad, aunque no se quiera reconocer, siguen rigiendo los campos ontológico y gnoseológico. Por muy radical que sea el planteamiento filosófico-epistemológico que se presente: escepticismo absoluto, nihilismo, solipsismo, relativismo, pragmatismo, esos principios continúan vigentes. No se pueden negar porque de hacerlo simplemente se cae en la ininteligibilidad, y por consecuencia en la imposibilidad de la comunicación, de la convivencia humana, y de la vida social en general.

Es ya conocida la formulación clásica del Principio de Razón Suficiente proporcionada por Leibniz:

Nuestros razonamientos se fundan en dos grandes principios: el de contradicción [...] Y el de razón suficiente, en virtud del cual consideramos que ningún hecho puede ser verdadero o existente y ninguna enunciación verdadera, sin que ello haya una razón bastante para que así sea y no de otro modo. Aunque las más veces esas razones no puedan ser conocidas por nosotros (Leibniz, 2001, §31-32).

Aunque una explicación de esta visión ontológica-gnoseológica de los principios de No-Contradicción, Identidad y Razón Suficiente se desarrollará posteriormente cuando se proponga como punto de partida de nuestro análisis epistemológico el realismo dialéctico hermenéutico, por el momento es necesario subrayar que el principio de Razón Suficiente no implica el reconocimiento de una causalidad mecanicista unidireccional, ni la adhesión al racionalismo clásico de Descartes, Leibniz, Spinoza, Malebranche, Wolff, o al movimiento de la Ilustración, o al mismo positivismo lógico, donde en todos ellos la razón se entiende como una ratio speculativa cuyo objeto es la verdad. Por el contrario, esa "razón” a la que apunta el principio aludido consiste en que todo evento, situación, estado de cosas, enunciado, tiene un origen, un porqué, aunque éste no sea exclusiva y estrictamente "racional" intelectualmente hablando, porque puede ser movido por la voluntad, la intencionalidad, el deseo, el gusto, la fe o la imaginación de un sujeto. Por ejemplo, la conducta de un enfermo de psicosis que pareciera totalmente irracional tiene su "lógica", la cual está regida por ciertas ideas obsesivas, alucinaciones, delirios, fobias, etc. que motivan que se comporte de determinada manera. Al conocer esa "lógica" es posible explicar y comprender por qué presenta ese comportamiento "anormal" como vestirse de determinada manera, hablar sólo, esconderse, reír o gritar sin aparente motivo, realizar ciertos rituales como lavarse las manos continuamente, incluso agredir.

En el caso académico que nos ocupa, cuando se declara la inviabilidad del fundacionismo es necesario publicar libros, artículos, defender tesis para "dar razones", justificar esas visiones contra el fundacionismo. Pero ahora, esas razones se encuentran dentro de la actividad de los científicos, sus intenciones, creencias, lenguajes, consensos, lo que convierte al autodeclarado anti-fundacionismo en un fundacionismo inmanente.

En efecto, para fundamentar el conocimiento científico ahora se recurre a los marcos referenciales (paradigmas, tradiciones) que las comunidades científicas eligen por consenso para desarrollar su actividad científica, por lo que la sociología del conocimiento se convierte en la herramienta teorética que permite comprender qué es y cómo se hace la ciencia (Kuhn, 1996; Laudan, 1986; Merton, 1973; Ziman, 1972); o bien se acude al pragmatismo para cumplir esa función justificativa (Buschman, 2017; Dewey, 1998; James, 2011; Peirce, 1986); o finalmente, se explica el fenómeno de la ciencia como una especie de conductismo 
epistemológico de la comunidad científica, donde el único acceso al mundo es la conversación con otros, es decir, un acceso intersubjetivo (Rorty, 1989, 1995).

O en otras vertientes se acoje "al giro lingüístico" deslindándose de los hechos: "no hay exactamente hechos, sino sólo interpretaciones. No podemos determinar ningún factum «en sí»” (Nietzsche, 2004, p. 170, Fragmento 7[60]), incluso también suprimiendo al sujeto en su afán de eliminar a un Sujeto Transcendental: “Es en fin, necesario poner todavía al interpretador detrás de la interpretación?” (Nietzsche, 2004, p. 170, Fragmento 7[60]). Por lo que una consecuencia de esa posición es permanecer cautivos en y por el texto: "el texto [...] sólo se produce en la transformación de otro texto. No hay nada [...] simplemente presente o ausente. No hay [...] más que diferencias y trazas de trazas» (Derrida, 1975, p. 393). Por lo que el texto se convierte en una realidad envolvente de la que no se puede escapar:

La obra de un individuo es una especie de nudo que se forma dentro de un tejido cultural y en cuyo seno el individuo se encuentra no solo inmerso, sino que aparece en él. El individuo es, desde el origen, un momento de este tejido cultural. Asimismo, una obra es siempre una obra colectiva. (Butor, 1969, p. 2).

En consecuencia, la creación se convierte en "una interacción textual que ocurre dentro de un texto separado [intertextualidad]. Para un sujeto cognoscente, la intertextualidad es un concepto que será signo de la forma en que el texto lee la historia y encaja en ella" (Kristeva, 1974, p. 443). Todo lo cual da origen a la pensée de citation, pensée citationnelle en la cual, la concatenación de citas es la forma de crear obras, todo discurso toma su argumentación de otros discursos, nunca de la realidad. La vivencia de la propia intertextualidad se expresa en el caos de citas que reflejan el "caos cósmico", donde reina "el proceso de desintegración del mundo de las cosas" (Hassan, 1971, p. 59).

Ahora bien, si todo es lenguaje, entonces la retórica es la que toma el lugar de la lógica y la verificabilidad; la verdad se aleja de la correspondencia del decir con el ser:

"Decir, en efecto, que el Ente no es o que el No-ente es, es falso, y decir que el Ente es y que el No-ente no es, es verdadero" (Aristóteles, 1998, 207). ${ }^{2}$ Aunque aún es posible hablar de la verdad de un discurso, ahora el sentido se disloca hacia el cómo se dice y no en lo que se dice, por lo que "la verdad no posee una naturaleza metafísica o lógica sino retórica" (Vattimo, 1988, p. 38).

Sin embargo, el seguir esta línea que niega la realidad, nos pone a la deriva sin un punto de orientación, como se expresa en Alicia en el país de la maravillas: «si te da igual a dónde ir, poco importa el camino que se tome» y la pregunta qué es la ciencia y su diferencia con otros modos de asimilar la realidad se difumina.

De esta manera, nos encontramos ante la encrucijada con la que nace la filosofía occidental: o existe el ser y los fundamentos metafísicos, con lo cual se desprende la necesidad, la inmutabilidad, la universalidad, la identidad, la unidad y la verdad; pero se niega el cambio, la diferencia y el contexto; o se reconocen estos últimos, pero entonces no se tiene un fundamento que nos ancle y se queda a la vaivén del eterno devenir, la diversidad, el relativismo y el riesgo de perder la común-unidad.

\subsection{Realismo dialéctico hermenéutico}

Ante ese dilema, proponemos como marco teorético de una epistemología que pueda responder a esos y otros problemas, lo que hemos denominado realismo dialéctico hermenéutico.

\subsubsection{Realismo}

Indiscutiblemente, reconocemos una realidad externa independiente del sujeto. Es extraño que sea necesario recordar y hasta defender esa tesis realista, que debería resultar obvia, además con el riesgo de ser calificados como "ingenuos" y metafísicos: "Los principios fundamentales y los postulados indispensables de 
toda ciencia genuinamente productiva no están basados en la lógica pura sino en la hipótesis metafísica [...] de que existe un mundo exterior que es totalmente independiente de nosotros." ${ }^{3}$ (Planck, 1932, p. 138) [resaltado nuestro], porque con palabras de Einstein: “QQuién se tomaría el trabajo de contemplar las estrellas si no creyera que existen realmente?” (Planck, 1932, p. 213). La cuestión es que no sólo se contemplan, sino se estudian. Desde ese planteamiento epistemológico podemos dejar como un buen ejercicio mental el agudo análisis que llega a la negación de la realidad externa, pero "una ciencia que comienza predicando la negación de la objetividad ya se ha sentenciado a sí misma” (Planck, 1932, p. 80).

Las dos últimas citas son de científicos ganadores de Premio Nobel que en realidad se han dedicado a hacer ciencia, realizado descubrimientos científicos y construido teorías que explican fenómenos de la realidad; y no de críticos profesionales o epistemólogos sólo dedicados a disquisiciones abstractas desde sus cubículos. Entonces, ¿cómo entender esas conclusiones antirealistas? Consideramos que debido a tres razones principalmente: a la exacerbación y consecuente crítica del principio empirista del positivismo; a la pretensión de querer demostrar lógicamente la existencia de la realidad externa; y a la ausencia de una visión dialéctica.

Con respecto al primer punto, podemos decir que generalmente cuando se realiza una crítica a cierta postura filosófica, artística, figura o momento histórico, se tiende a negar todo en bloque sin rescatar momentos positivos que se puedan rescatar y llevando hasta el extremo algunos momentos o ideas, lo que da como resultado la pérdida de su valor inicial e incluso conduce a sinsentidos. Por ejemplo, si volteamos la mirada a la historia del arte descubrimos que como reacción a los excesos del barroco surgió su antípoda, el neoclasicismo; cuando se exageró en el orden y la medida, el neoclasicismo cedió el lugar al romanticismo; a este último a su vez sucedió el realismo; después del realismo apareció el surrealismo, el neoromanticismo y otros movimientos contrarios. Del mismo modo, en la historia se llega a construir por parte de los críticos una figura totalmente negativa del objeto de la crítica; así por ejemplo, los emperadores romanos posteriores a Nerón crearon una imagen de este como un personaje hedonista, déspota, narcisista, artista fracasado, que incluso sufría de sus facultades mentales y fue culpable del incendio de Roma. Asimismo, en el Renacimiento, para reafirmar su posición se criticó duramente a la edad media, haciéndola aparecer como una época del oscurantismo religioso sin ninguna aportación positiva al desarrollo de la ciencia y de las ideas. Podemos afirmar que algo semejante sucede con la crítica al Positivismo.

En efecto, el Positivismo como corriente epistemológica dominante ha sido objeto de crítica por su exaltación del monismo metodológico centrado en las ciencias naturales dejando desprotegidas a las ciencias humanas y sociales, su supuesta objetividad absoluta y su racionalidad instrumental que concibe al conocimiento como herramienta transformadora. Pero dicha crítica envuelve del todo al Positivismo, se exageran algunos puntos de su postura que conducen a sinsentidos y se olvidan otros que resultaron grandes aportaciones y avances.

Una de esas aportaciones fue su exigencia de dejar a un lado los escritos que se tenían como fuentes de conocimiento y autoridad indiscutible para voltear la mirada a los hechos positivos. Es difícil no sobrevalorar la simple petición de Galileo a sus jueces: "sólo vean el cielo a través de mi telescopio". Si se observa la realidad, se constata que la luna tiene montañas, valles, cráteres, y no era de materia perfecta como Aristóteles suponía era el mundo supralunar. Asimismo, se podía verificar que Júpiter tenía lunas, las cuales giraban alrededor de él, que Venus tenía fases solo explicables por su translación alrededor del sol; por lo que se infería que la tierra de igual manera giraba alrededor del sol, no al contrario, como se afirmaba en la Biblia. Pero también no es fácil comprender el rechazo de los oponentes ante tal argumento: "no necesito ver el cielo a través de ese tubo" porque tengo la Biblia, los escritos de Aristóteles y todos sus comentaristas.

Sin embargo, ese principio para desarrollar la actividad científica: volver los ojos hacia la naturaleza despegándolos de los libros, en sí mismo progresista, se basa en la tesis empirista de que el origen del conocimiento son los datos que proporcionan los sentidos, y como las sensaciones son subjetivas, a fin de cuentas lo que se tiene es una imagen del subjetiva del mundo, en el mejor de los casos, o un idealismo subjetivo 
del tipo de Berkeley, donde las sensaciones crean el mundo en el peor de los escenarios. De esta manera, si se llega a extrapolar ese principio y se niega, pareciera que el "giro lingüístico" en filosofía nos regresa a una etapa pregalileana donde el imperativo de ver la naturaleza es desoído porque no hay hechos, sólo interpretaciones, todo es texto y no es necesario ver a través de ese tubo si se tiene una red de significados que nos llevan a otro significado.

Esa tesis antirrealista parece reforzarse por los descubrimientos de la física cuántica, el principio de incertidumbre de Heisenberg, ${ }^{4}$ el principio de complementariedad de Bohr, ${ }^{5}$ la paradoja de Schrödinger, ${ }^{6}$ que ha llevado a concluir que está científicamente comprobado a nivel cuántico que la realidad objetiva no existe $^{7}$ y los principio lógicos y ontológicos a los que hemos hecho alusión líneas arriba (no contradicción, identidad, tercer excluido y razón suficiente) no son universales.

Es evidente que existe algo como "un barranco profundo entre la evidencia empírica y las categorías que utiliza el discurso científico para representar la realidad” (Madera Gómez, 2016, p. 116). Ante estos últimos señalamientos podemos decir, siguiendo a Max Born, que la incoherencia entre las características de la realidad cuántica y las formas del pensamiento humano para representarlas y comprenderlas se debe más bien a que el sistema cognitivo no sólo del ser humano, sino incluso de otros animales que interactúan con el medio ambiente, funciona para entender el mundo macroscópico y no fue diseñado para enfrentarse a otra realidad que aparece de diferente manera: "deberíamos, no tratar de modificar o abandonar el realismo ingenuo, sino restringirlo a las dimensiones ordinarias, para las que el cuerpo y la mente humanos han sido adaptados biológicamente" (Born, 1972, p. 200).

El afirmar que un sistema físico es y no es a la vez, que la realidad objetiva no existe, es inteligible, si y sólo si, no es verdad la negación de esas afirmaciones, es decir, si funciona el principio de no contradicción, porque de lo contrario

colapsaría cualquier intento de comunicación, expresión lingüística, pensamiento o acción. [...] de facto los animales, en su conducta, manifiestan [...] una lógica de la identidad y la diferencia. [...] si de algún modo, no se respetara la lógica de la identidad y la diferencia no podría existir, al menos, vida animal superior (Casabán Moya, 2003, p. 61).

Por lo que respecta a la subjetividad de las sensaciones e incluso el peligro de caer en el idealismo subjetivo, también es necesario recurrir a la existencia de la realidad externa que produce la excitación de los sentidos. Indiscutiblemente las sensaciones son subjetivas pero la fuente de ellas es común e independiente del sujeto.

La sensación, en efecto, no es, ciertamente, sensación de sí misma, sino que hay también, además de la sensación, otra cosa, que necesariamente es anterior a la sensación, pues lo que mueve es por naturaleza anterior a lo que es movido" (Aristóteles, 1998, p. 201). ${ }^{8}$

De ahí que se pueden distinguir las alucinaciones, los sueños, los errores de otras sensaciones que realmente informan sobre el mundo. Podemos recurrir al así llamado "argumento evolucionista" que indica la veracidad de la información de los sentidos que alertan sobre la presencia del predador y los peligros en general para alejarse de ellos, de lo contrario simplemente se extinguirían como especie. A nivel abstracto se puede discutir si existe o no esa realidad externa que se percibe y si la percepción del otro es la misma que la de uno; pero ante la presencia del león, el fuego, el barranco, el virus del VIH, del ébola o COVID19, simplemente hay que prevenirse o combatirlos. No es una discusión epistemológica, es una decisión de vida.

En lo referente a la segunda causa de la tesis antirrealista de pretender demostrar lógicamente la existencia de la realidad externa y al no lograrlo se niega dicha realidad, simplemente podemos constatar que esa exigencia es imposible de realizarla porque se encuentra fuera de la lógica, lo único que se puede hacer es mostrarla. La demostración lógica es un proceso de inferencia(s) a partir de enunciados iniciales llamados premisas. Si se quiere demostrar todo, entonces es necesario demostrar esas premisas, pero para hacerlo se requieren otras premisas, las cuales a su vez deben ser demostradas con ayuda de otras premisas, repitiendo el proceso de manera infinita. Por ello se afirma que "quien quiere demostrar todo, nada demuestra". Para 
romper ese proceso ad infinitum es necesario tener unos principios que no necesitan ser demostrados, en la lógica a esos enunciados primitivos se les denomina axiomas; en teoría del conocimiento son los hechos, los objetos existentes independientemente del sujeto, la conciencia de uno y del otro. Max Planck llama teorema a ese principio: "hay un mundo real exterior que existe independientemente de nuestro acto de conocimiento" (Planck, 1932, p. 82), y Einstein concuerda con esa idea: "En esto estoy completamente de acuerdo con Planck. Nosotros no podemos lógicamente demostrar la existencia del mundo exterior, como tampoco podemos probar lógicamente que yo estoy hablando con usted y que me encuentro aquí" (Planck, 1932, p. 213).

Así pues, el sujeto no es creador del ser, aunque como se verá por la dialéctica y la hermenéutica, al mismo tiempo es constructor de ciertos "modos" de ser de un ser que ya es. De esta manera, se reconoce la primacía ontológica, primero ser y después conocer, valorar, actuar, informar, etcétera, lo que nos da la posibilidad de alejarnos del relativismo, subjetivismo, solipsismo.

Finalmente, la tercera causa que hemos aducido sobre la aparición de la tesis antirrealista, la ausencia de una visión dialéctica, nos conduce a exponer la segunda característica de nuestra visión del realismo dialéctico hermenéutico: la dialéctica.

\subsubsection{Dialéctica}

Al conceder la primacía del ser objetivo al mismo tiempo reconocemos que ese ser es infinito, complejo y dinámico, no uniforme ni monolítico, sino contiene en sí contrarios: A y noA. Con la particularidad de que noA no necesariamente es el polo opuesto de A (blanco-negro; alto-bajo, bueno-malo, feliz-infeliz, normalanormal, ...), sino su negación en el sentido lógico (no blanco no significa necesariamente negro, o no alto es bajo, no bueno es malo, no feliz es infeliz, no normal es anormal, ...). Debido a que, a la dialéctica ontológica, dialéctica del ser, le corresponde una dialéctica gnoseológica, dialéctica del conocer, la anterior característica de la unidad de los contrarios sin que puedan llegar a opuestos, nos permite evitar tener una visión dicotómica reduccionista de la realidad; el mundo no es bivalente sino multivalente, mucho más rico que se escapa a un código binario para captarlo. El decir que algo no es blanco (o no es negro o algún otro color) quiere decir que puede tener toda la gama que el espectro electromagnético ofrezca -para quienes puedan captarlo- y que para los colores visibles para el ojo humano se encuentra entre los límites del violeta y el rojo. Asimismo, esa aseveración de que algo no es blanco (o negro o algún otro color) puede indicar que tal vez en cierto momento, parte, en determinada circunstancia sí sea blanco (o negro o algún otro color) pero no del todo, lo que no invalida su blancura en esa parte, momento, circunstancia.

En el ámbito de la epistemología esta visión dialéctica nos proporciona la posibilidad de criticar sin aniquilar al positivismo u otras propuestas epistemológicas, reconocer sus ideas que han resultado benéficas y al mismo tiempo poder acercarse a otras corrientes (pragmatismo, funcionalismo, estructuralismo, fenomenología, hermenéutica, semiótica, etc.) buscando sus puntos positivos y desechando los que no lo son, para de esta manera, acercarse más a una comprensión de lo que es la ciencia.

Otro aspecto de la dialéctica como la concebimos es que esos contrarios presentes en la realidad (objetos, fenómenos, procesos) no se encuentran en lucha que requiere ser resuelta en un tercer momento como en la dialéctica hegeliana donde aparece la síntesis que resuelve la contradicción, sino que coexisten permanentemente e incluso se necesitan mutuamente para existir, ya que uno no puede existir sin el otro. En esa coexistencia de contrarios no se absolutiza alguno de ellos y se desecha el otro, lo que permite tener una comprensión más adecuada de la realidad sin caer en el dogmatismo absoluto o en el relativismo absoluto. Es por eso que desde esta posición dialéctica podemos conciliar el fundacionismo sin que estemos buscando unos fundamentos últimos e inamovibles, con la crítica antifundacionista que exalta el momento subjetivo y el contexto, sin caer en la negación total de la existencia de los fundamentos. Asimismo, nos ayuda a comprender otros pares de contrarios dentro del análisis de la ciencia como son la tradición y la innovación científica, lo 
teórico y lo histórico, la relación de la teoría con la observación, la comprensión y la razón instrumental, lo universal y lo contextual, el conocimiento del ser y su parte desconocida, entre otras muchas.

\subsubsection{Hermenéutica}

Por último, ese ser inicial que reconocemos en concordancia con el realismo del que partimos también es un ser hermenéutico porque no es un ser terminado, completo, que se da totalmente en un acto contemplativo, donde el sujeto lo recibe pasivamente; sino es un ser al que el sujeto le otorga sentido(s) en la acepción de construcción, no de creación ex nibilo, porque se parte del ser, que es, y el ser humano lo interpreta, sin distorsionarlo, sino respetando ese ser inicial, agregándole el cómo es para él.

De esta manera, en este momento, la visión hermenéutica y dialéctica confluyen porque se presentan dos momentos contrarios: hay algo nuevo y a la vez algo que viene dado; no hay pura creación: "no hay hechos, sólo interpretaciones", ni tampoco hay mera repetición donde el intelecto es reflejo de la naturaleza.

Esa prioridad del ser puede ser entendida utilizando el pensamiento del segundo Heidegger, donde el ser se presenta, se manifiesta, habla, y requiere ser escuchado e interpretado (Heidegger, 2005). En la escucha, el ser humano va des-cubriendo el ser gracias a la construcción de sentidos desde un contexto histórico social- cultural concreto, el cual contiene sus particulares creencias, costumbres, valores, lenguaje, conocimientos previos, tradiciones de investigación, etcétera. Dicho contexto es llamado por Gadamer horizonte hermenéutico, e incluye pre-juicios y tradiciones, desde donde se ve e interpreta esa realidad. Gracias a esa construcción de sentidos se construye al mismo tiempo el mundo eminentemente humano, la cultura. Así pues, ese proceso no es exclusivamente antropológico ni tampoco eminentemente ontológico, sino su conjunción: onto-antropológico (Gadamer, 1997).

\section{Conclusiones}

La epistemología dialéctica que proponemos, derivada del realismo dialéctico hermenéutico, resulta una herramienta muy útil para el análisis de la ciencia en general y de la ciencia de la Información en particular. Su aplicación permite entender, por ejemplo, la aparición de algunas "ciencia de la información" localistas, como la iberoamericana o la latinoamericana; o que ofrecen la voz a minorías, "ciencia de la información" amerindia, afroamericana, feminista, porque lo universal y particular se ven desde la tensión dialéctica de los contrarios y se admite la validez de ambos.

Asimismo, se llega a comprender un concepto clave como el de información que contiene elementos subjetivos en su construcción, pero sin llegar al relativismo subjetivo absoluto; o a la tentación de un paninformacionismo sin la participación del sujeto.

De la misma manera, es posible comprender la evolución de la ciencia de la información, su interrelación con otras disciplinas informativo-documentales como la archivística, la bibliografía, la biblioteconomía, la ciencia de la documentación y la museología. Otro problema que puede ser tratado satisfactoriamente es la existencia de la multidisciplina, la interdisciplina y la transdisciplina sin perder la disciplina.

Desde este marco filosófico podemos proporcionar la debida interpretación al paso por diferentes etapas, enfoques, concepciones o como les gusta decir a algunos, paradigmas, como son los ya tres conocidos paradigmas físico cognitivo y social mencionados por Capurro (2007); o los dos, propuestos por Silva y Ribeiro (2002) custodial y postcustodial; o los siete, según Hjørland (2018), el paradigma ateórico, la teoría matemática de la comunicación de Shannon y Weaver, la tradición de Cranfield, el paradigma bibliográfico, la visión cognitiva; la filosofía de la información de Floridi; y los acercamientos social, cultural y de contenido. Desde la epistemología dialéctica se conciben no como una secuencia lineal escalonada, sino como un movimiento espiral, donde lo antiguo y nuevo se cruzan; se excluyen, aunque no totalmente; pero también 
se incluyen porque se conservan algunos momentos de los anteriores, aunque con algunas variaciones; e incluso se necesitan mutuamente para desarrollarse. El paradigma custodial no es el mismo en el siglo XIX que en el XXI, donde ya predomina el paradigma post-custodial, pero no ha desaparecido del todo y los instrumentos de conservación y custodia se han actualizado. De la misma manera se pueden interpretar diferentes concepciones dentro del campo informativo documental, como pueden ser un enfoque humanista, tecnológico, mercadotécnico, consumista, administrativo, instrumentalista, entre otros muchos. Todos ellos pueden coexistir en tensión, sin absolutizar ni eliminar alguno de ellos, todos tendrán un momento positivo que aportar y se relacionarán dialécticamente.

Si seguimos este modelo dialéctico, es posible analizar el descarte y la conservación, la memoria y el olvido, la desinformación como posible información útil, el complejo proceso informativo documental que incluye aspectos comunicacionales, científicos, técnicos. En fin, sólo queda la imaginación e iniciativa del investigador que se adentre al análisis epistemológico de la ciencia de la información armado con esta herramienta para elegir y plantear los problemas que desee estudiar y proponer sus respuestas.

\section{REFERENCIAS}

Aristóteles. (1998). Metafísica. Madrid: Gredos.

Beth, E. W. (1975). Las paradojas de la lógica. Valencia: Universidad de Valencia.

Born, M. (1972). Reflexiones de un físico. Revista de la Dirección de Divulgación Cultural Universidad Nacional de Colombia, 11, 197-205.

Buschman, J. (2017). Once more unto the breach: “Overcoming epistemology” and librarianship's de facto Deweyan Pragmatism. Journal of documentation, 73(2), 210-223. https://doi.org/10.1108/JD-04-2016-0052

Butor, M. (1969). Preámbulo. Revue L'Arc, 39.

Capurro, R. (2007). Epistemología y ciencia de la información. Enl@ce: revista venezolana de información, tecnología y conocimiento, 4(19), 11-29.

Casabán Moya, E. (2003). Sobre la naturalización de la lógica. Revista de filosofía, 28(1), 59-75.

Chéjov, A. (2013). Carta a un vecino erudito. En P. Viejo (ed.) Cuentos completos (Tomo 1). Madrid: Páginas de Espuma.

Derrida, J. (1975). La diseminación. Madrid.

Dewey, J. (1998). The problem of truth. In L. A. Hickman and T.M. Alexander (Eds.), The essential Dewey (Vol. 2, pp. 101-130). Bloomington, Indiana: Indiana University Press.

Frege, G. (1984). El pensamiento. Una investigación lógica. En Investigaciones lógicas (pp. 49-85). Madrid: Tecnos.

Gadamer, H-G. (1997). Verdad y método I. Fundamentos de una hermenéutica filosófica. Salamanca: Sígueme.

Hassan, I. H. (1971). The dismemberment of Orpheus: toward a postmodernist literature. New York: Oxford University Press.

Heidegger, M. (2005). Hölderlin y la esencia de la poesía. En Aclaraciones a la poesía de Hölderlin (pp. 37-53). Madrid: Alianza Editorial.

Hjørland, B. (2018). Library and information science (LIS). En B. Hjørland y C. Gnoli (eds.) ISKO Encyclopedia of Knowledge Organization. Recuperado de https://www.isko.org/cyclo/lis.htm\#top.

James, W. (2011). El significado de la verdad. Barcelona: Marbot Ediciones.

Kristeva, J. (1974). La revolution du langage poetique: l'avant-garde a la fin du XIXe siecle. París: Seuil.

Kuhn, T. (1996). La estructura de las revoluciones cientificas. México: FCE.

Laudan, L. (1986). El progreso y sus problemas: hacia una teoría del crecimiento cientifico. Madrid: Encuentro.

Leibniz, G. W. (2001). Monadologia: principios de filosofía. Barcelona: Biblioteca Nueva.

Madera Gómez, S. (2016). Niels Bohr: complementariedad, identidad y contradicción en lógica. Sophia, colección de filosofia de la educación, 21(2), 101-118. DOI: https://10.17163/soph.n21.2016.04 
Merton, R. K. (1973). The sociology of science: theoretical and empirical investigations. Chicago: The University of Chicago.

Nietzsche, F. (2004). Fragmentos póstumos. Una selección. Madrid: ABADA Editores.

Parménides. (1985). Sobre la naturaleza. En A. Gómez Lobo. Parménides. Texto, traduccióny comentario. Buenos Aires: Charcas.

Peirce, Ch. (1986). How to make our ideas clear. En C. J. W. Kloesel (ed.) Writings of Charles S. Peirce: a chronological edition (Vol. 3, pp. 257-276). Bloomington, Indiana: Indiana University Press.

Planck, M. (1932). Where is science going? New York: W. W. Norton and Company Inc. Publishers.

Popper, K. (1980). Three worlds. Delivered at the University of Michigan, April 7, 1978. En E. Ashby, et al., The Tanner lecture on human values (pp. 141-167). London: Cambridge University Press. Recuperado de https:// tannerlectures.utah.edu/_documents/a-to-z/p/popper80.pdf

Proietti, M., Pickston, A., Graffitti, F., Barrow, P., Kundys, D., Branciard, C., Ringbauer, M. \& Fedrizzi, A. (2019). Experimental test of local observer independence. Science advances, 5(9). Recuperado de https://advances.scien cemag.org/content/5/9/eaaw9832

Rendón Rojas, M. Á. (2005). Bases teóricas y filosóficas de la Bibliotecología. México: Centro Universitario de Investigaciones Bibliotecológicas, UNAM.

Romero, C. M.(1981). Algunas consideraciones sobre epistemología cientifica. San José de Costa Rica: Escuela de Trabajo Social, Universidad de Costa Rica. Recuperado de http://www.ts.ucr.ac.cr/binarios/docente/pd-000186.pdf

Rorty, R. (1989). Contingency, irony, and solidarity. London: Cambridge University Press.

Rorty, R. (1995). La filosofía y el espejo de la naturaleza. Madrid: Cátedra.

Saraiva Cruz, I. (2020). Fundacionismo y ciencia de la información: una revisión crítica. Informatio. Revista del Instituto de Información de la Facultad de Información y Comunicación, 25(1), 30-57. https://doi.org/10.3564 3/Info.25.1.2

Silva, A. M. y Ribeiro, F. (2002). Das "ciências" documentais à ciência da informação. ensaio epistemológico para um novo modelo curricular. Porto: Edições Afrontamento.

Vattimo, G. (1988). Dialéctica, diferencia y pensamiento débil. En G. Vattimo y P. A. Rovatti (eds). El pensamiento débil (pp. 18-42). Madrid: Cátedra.

Wittgenstein, L. (2002). Tractatus lógico-philosophicus. Madrid: Tecnos.

Ziman, J. M. (1972). Conocimiento público. Un ensayo sobre la dimensión social de la ciencia. México: Fondo de Cultura Económica.

\section{Notas}

1 Entre las paradojas lógicas se encuentran la de las clases y la de las propiedades descubiertas por Russell. La paradoja de las clases consiste en que la clase de todas las clases no contenidas en sí mismas se contiene a sí misma si y sólo si no se contiene a sí misma. La paradoja de las propiedades indica que la propiedad de ser impredicable (o propiedad que no se aplica a sí misma) es predicable (o se aplica a sí misma) si y sólo si no es predicable. Una paradoja semántica es la llamada del mentiroso atribuida inicialmente a Epiménides el cretense, quien afirmó "todos los cretenses mienten", por consecuencia, Epiménides miente si y si solamente dice la verdad, y dice la verdad si y sólo si miente. La versión contemporánea de esta última paradoja se reformula con "yo miento" y el resultado es el mismo. En Beth (1975) se encuentra un listado de las paradojas, así como su análisis.

2 Aristóteles. Metafisica, $1110 \mathrm{~b}$.

3 Resulta paradójico que el reconocimiento de la realidad externa e independiente del sujeto se reconozca como algo metafísico, ya que por su etimología, la metafísica es lo que está más allá de lo físico y lo que se está reconociendo es precisamente lo físico, no lo que está fuera de ese campo.

4 Es imposible determinar exactamente al mismo tiempo la posición y la velocidad de un objeto subatómico. Si se conoce la posición, se afecta la velocidad; y si se conoce la velocidad, se desconoce la posición. 
5 Todo fenómeno físico a nivel cuántico posee simultáneamente una dualidad incompatible, dos naturalezas contradictorias: onda/partícula o posición/momento cinético que aunque son mutuamente excluyentes coexisten como superposiciones porque son necesarios para describir la totalidad de los fenómenos.

6 Dos estados de cosas contradictorias (vida o muerte del famoso gato) tienen el $50 \%$ de probabilidades de suceder cada uno. Mientras no exista un observador que lo constate, se puede decir que esas posibilidades coexisten en la conocida superposición (el gato está vivo y muerto a la vez). En el momento que un observador irrumpe para constatar cuál de esas dos posibilidades ocurrió, la superposición se rompe y es posible decir que el gato está vivo o muerto.

7 Eugene Wigner describió un experimento mental que demostró que dos observadores experimentan diferentes realidades. En 2009 un equipo de investigadores informó que lograron recrear dicho experimento mental en condiciones de laboratorio, por lo que se demostró la propuesta de Wigner que no existe una realidad objetiva. (Proietti, et al., 2019).

8 Aristóteles. Metafísica, 1110a. 